\title{
A new pump selection method for large-power PV irrigation systems at a variable frequency
}

R.H. Almeida ${ }^{1,2, *}$, J.R. Ledesma ${ }^{1}$, I.B. Carrêlo ${ }^{1}$, L. Narvarte ${ }^{1}$, G. Ferrara $^{3}$, L. Antipodi ${ }^{3}$

${ }^{1}$ Instituto de Energía Solar - Universidad Politécnica de Madrid, 28031 Madrid, Spain

${ }^{2}$ Instituto Dom Luiz, Faculdade de Ciências, Universidade de Lisboa, 1749-016 Lisboa, Portugal

${ }^{3}$ CAPRARI SPA, Modena, Italy

*Phone: +34 913365531; E-mail: rita.hogan@ies.upm.es

\begin{abstract}
This paper presents a new method for selecting a pump for large-power PV irrigation systems working at a variable frequency. This can have a significant impact since the traditional way of selecting the pump is based on maximizing the efficiency of pump in the duty point at a certain single operating frequency, which is not useful for PV irrigation systems working at a variable frequency. The proposed method starts by considering the pumps with H-Q curves with a high slope and the duty point in the right-hand third of the curve to assure a wide range of operating frequencies. Then, the efficiency within the whole range of frequencies is evaluated. An example of a performance comparison between the pumps selected with the new and traditional methods has been carried out. Results show that by using the new method, the yearly volume of water pumped increases by $7.2-21.0 \%$ and the pump efficiency by $4.3-5.3 \%$. Finally, it is important to mention that the proposed method has already been implemented in the SISIFO tool, able to simulate PV irrigation systems.
\end{abstract}


Keywords: Photovoltaic; PV irrigation systems; Pump selection method; Variable frequency; Water pumping

\section{Introduction}

The market for large power photovoltaic (PV) irrigation systems (from $40 \mathrm{kWp}$ to $1 \mathrm{MWp}$ ) is growing [1], [2], [3], [4], [5], [6], [7], [8] mainly because technical and economical barriers [9] have been removed. Technical solutions for solving the problems associated with PV-power intermittences have been developed without using batteries, taking advantage of the energy regeneration of the pumps [10]. Furthermore, the use of North-South horizontal axis solar trackers, that provide a constant daily profile of PV power, allows a better matching with the dynamic of the well [11], [12], [13]. Finally, the decrease in the cost of the PV module [14], the exclusion of batteries and the increase in the price of conventional electricity [15], [16] makes this solution more competitive [17], [18], [19], [20] with some real-scale experiences showing cost savings of $80 \%$ [7], [21].

Many authors have given much attention to the design [22], [23], [24], [25], [26], sizing [27], [28], [29], [30], [31], and optimization [23], [28] of PV irrigation systems. There are also some specific works regarding the modelling of the motor-pump subsystem [32], [33], [34].

These systems are basically made up of a PV generator, a frequency converter and a standard centrifugal pump [35]. Water is elevated to a water pool using the pump. The frequency of the pump and, therefore, the water flow into the pool, is variable and depends on the instantaneous PV-power available. The higher this PV power, the higher the frequency and, consequently, the water flow. This is the main difference with the 
traditional irrigation systems supplied by the grid or diesel generators that usually work in the same duty point, providing constant water flow [36].

So, the traditional way of selecting the appropriate pump is just to look for the pump that shows the highest efficiency just at this duty point (usually at 50 or $60 \mathrm{~Hz}$ ) [37]. The objective of the pump selection procedure is to maximize the efficiency, i.e. that the duty point and the point of maximum efficiency are as close as possible. In fact, professional irrigator communities, in their maintenance tasks, periodically extract the pump from the well after a certain number of hours of operation and refurbish the impellers and/or diffusers or replace them with new ones, in order to increase the efficiency at the duty point even if this means reducing efficiency at other working points that are not used.

However, this usual way of selecting is not valid for PV irrigation systems because they work at different frequencies and therefore at different working points.

This paper proposes a new way of selecting a pump suitable for PV irrigation applications at a variable frequency that is based on considering not only the efficiency at the maximum operating frequency but in the whole range of operating frequencies. This new method also allows considering pumps that widen the range of operating frequencies and, therefore, enlarge the daily number of hours of irrigation and increase the volume of water pumped during low irradiation periods.

As it influences the performance of the system, this paper not only describes the new method but also shows how it affects the final performance. For this, the yearly water pumped by two pumps selected with the traditional method and with the new method proposed here has been simulated for three locations with different climatic conditions, 
showing the improvement in the performance associated to this new pump selection method.

The impact of the way of selecting a pump on the performance of the system is shown for PV irrigation systems pumping into a water pool but it can also be applied to direct pumping to the irrigation network, which usually is carried out with sprinklers, pivots or drip systems. Direct pumping requires constant pressure and water flow which also means constant power. But the reality is that one single irrigation network includes several sectors with different values of constant pressure and water flow. So, different powers are needed but, in this case, it does not depend on the instantaneous PV-power available but on the sector being irrigated. In any case, the pump must also work at different frequencies and working-points.

This new method has been implemented in SISIFO (www.sisifo.info), a simulation tool developed within the framework of a real-scale demonstration project of large-power irrigation systems [21]. The implementation of this method in this tool is also shown.

\section{The traditional pump selection method}

The following items need to be taken into account to select the appropriate pump for an irrigation system:

- The total manometric head (HMT) against which the pump must operate. The HMT is the addition of the static level of water in the well $\left(\mathrm{H}_{\mathrm{st}}\right)$, the drawdown of the water level at a certain water flow, the friction losses in the pipes and the height of the water tank $\left(\mathrm{H}_{\text {pool }}\right)$ (see Fig 1). $\mathrm{H}_{\mathrm{st}}$ is the level at which the free water surface is positioned in the well at zero pump flow. Frequently, $\mathrm{H}_{\text {st }}$ plus drawdown is called the dynamic level of water in the well $\left(\mathrm{H}_{\text {dyn }}\right) . \mathrm{H}_{\text {dyn }}$ is the 
level at which the water is positioned in the well at a determined flow. The relationship between $\mathrm{H}_{\text {st }}$ and $\mathrm{H}_{\text {dyn }}$ is a characteristic of each well and is mainly a function of the nature of the soil and the water veins contained therein.

- The maximum flow rate. This value is usually determined by the well and/or by the diameter of the pipes of the existing irrigation network.

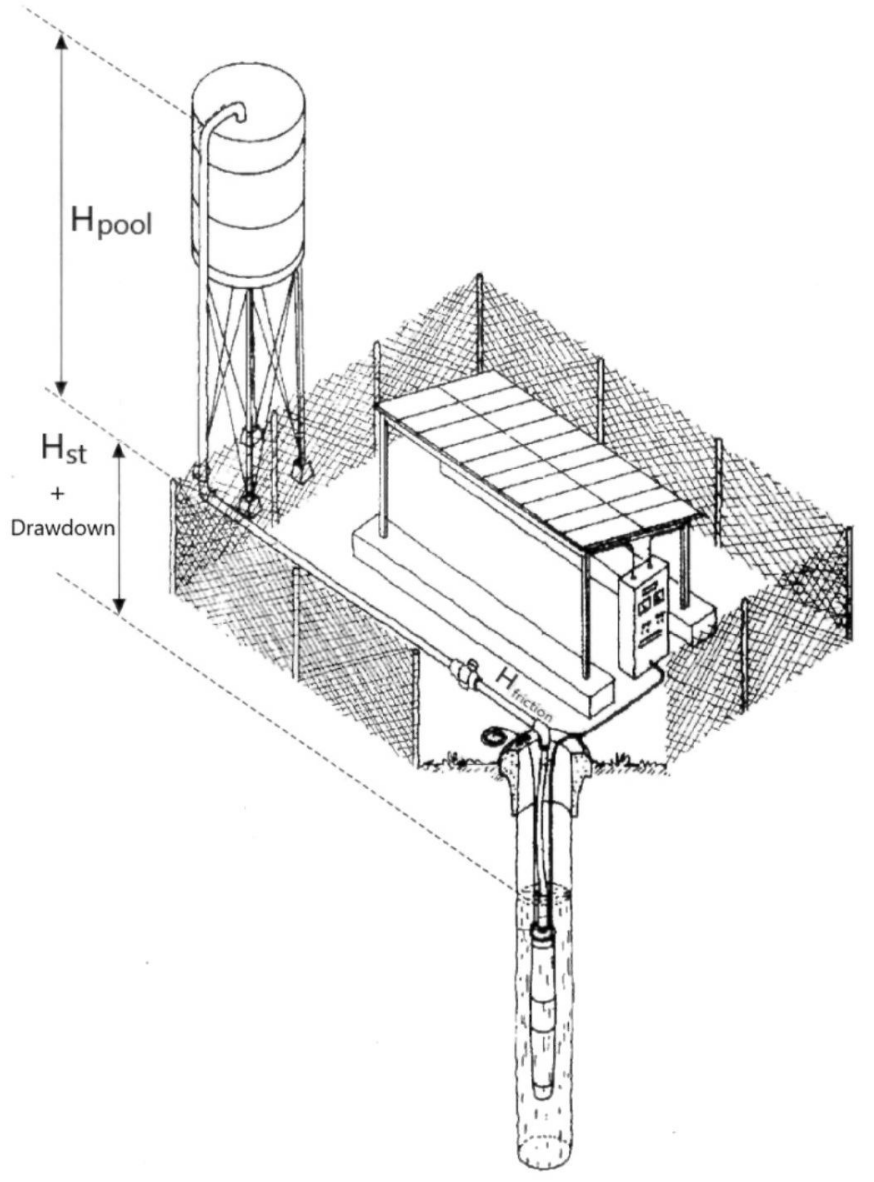

Fig.1. PV pumping system from a well to a water tank. The figure illustrates the static head $\left(\mathrm{H}_{\mathrm{st}}\right)$, the drawdown and the head of the water tank, $\left(\mathrm{H}_{\text {pool }}\right)$. The total manometric head is the addition of $\mathrm{H}_{\text {st }}$, drawdown, $\mathrm{H}_{\text {pool }}$ plus the friction losses. 
This information allows the system curve and the duty point to be identified. The "system curve" is a graphical representation of the relationship between the pumping head, taking into account the friction losses in the pipes of the irrigation system, and the flow rate. It is completely independent of the pump characteristics and its basic shape is parabolic. If $\mathrm{H}_{\mathrm{st}}$ is zero, it will start at the point zero water flow (Q) and zero pumping head $(\mathrm{H})$; otherwise the curve will be vertically offset from the zero to $\mathrm{H}_{\mathrm{st}}$. In a generic system curve this point is called the "geodetic head" and it represents the height between the water withdrawal point and the ground.

The duty point is the intersection between the H-Q curve of the pump and the system curve. Also referred to as the "operating point", it indicates the values of $\mathrm{H}$ and $\mathrm{Q}$ that will be obtained at stationary operation with the respective speed-related pump Q-H curve and it is defined to be that point in the H-Q curve system for which a pump is to be selected.

In the traditional pump selection method, the objective is to minimize the deviation between the specified and the actual duty points, and to choose a pump with the best efficiency point (BEP) as close as possible to the duty point (see Fig 2). BEP corresponds to the water flow which the hydraulic passages in the pump were designed for, where the speed of the fluid most closely matches the geometries of the impeller and the casing, where the pressure distribution around the impeller(s) is symmetrical and where hydraulic passage entry and exit are the smoothest. 


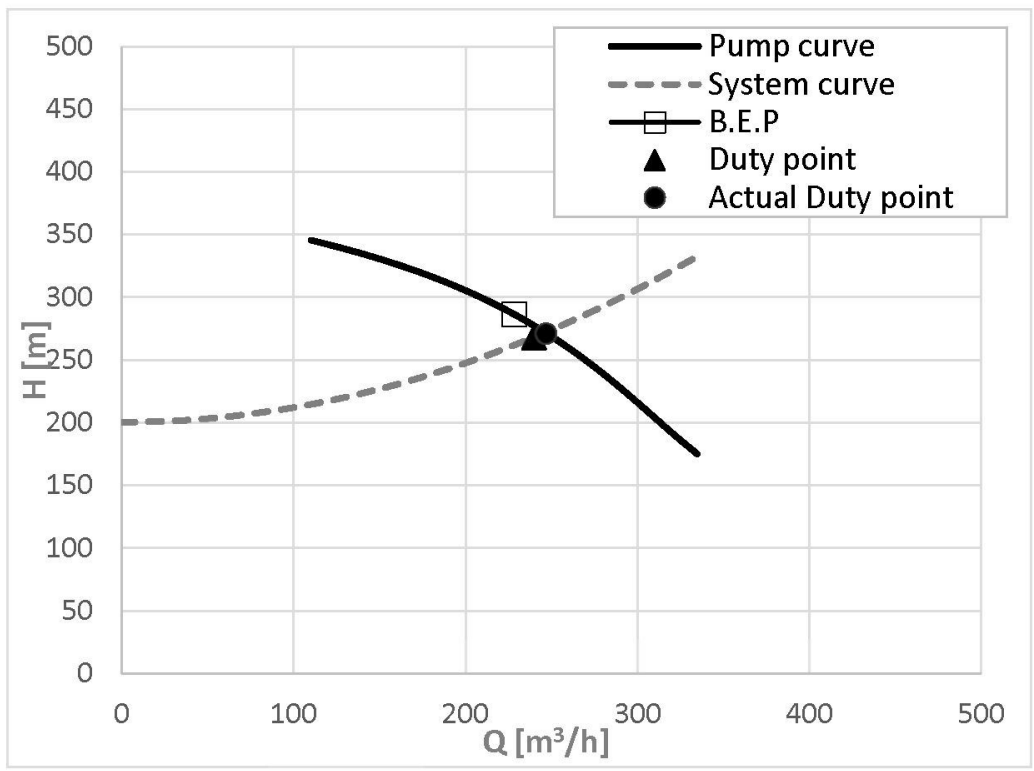

Fig.2. System curve, H-Q pump curve and characteristic points to select a pump.

It is usually possible to find several pumps suitable for a specific duty point but, while the "correct selection" has its BEP in the proximity of the duty point, the other pumps may have it too far to the "right" or to the "left" of the duty point (see Fig 3).

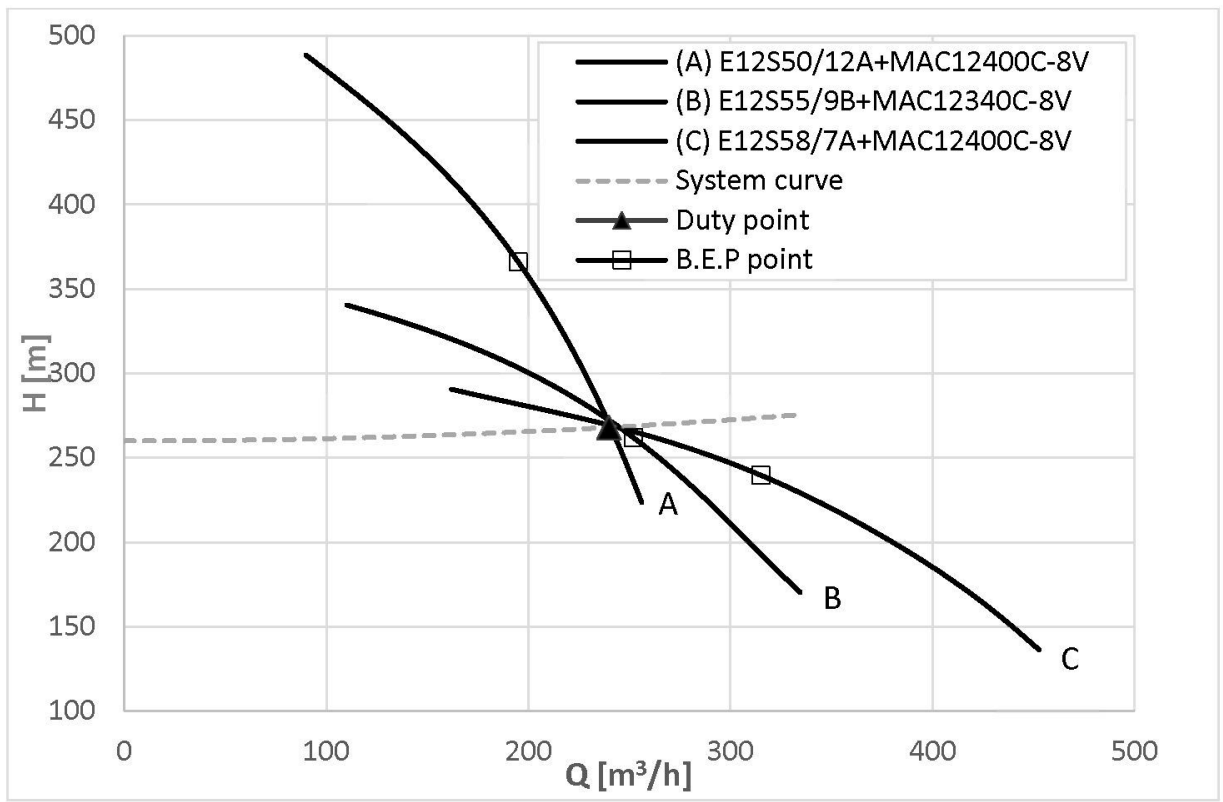


Fig.3. Three possible pumps for a certain duty point. Pump A has its BEP too far to the left in respect to the duty point; Pump C has its BEP too far to the right in respect to the duty point. Pump B has the BEP close to the duty point and the pump would be the selected according to the traditional pump selection method.

According to the traditional pump selection method, pump B in Fig 3 is to be preferred because the BEP is close to the duty point. This pump should always be selected so that it operates predominantly close to the BEP in the so-called "preferred operating region" (Fig 4). This mode of operation is apt to bring about the lowest energy and maintenance cost and to reduce the risk of system problems since hydraulic excitation forces and cavitation risk attain a minimum close to the BEP [38]. Operating away from BEP moves the speed profiles away from this ideal, leading to compromised flow, inevitable turbulence and recirculation [39]. In the pump selection documentation provided by a pump manufacturer, normally, only the "Allowable operating region" is generally indicated while the "Preferred operating region" is generally derived from the efficiency of the BEP minus five points.

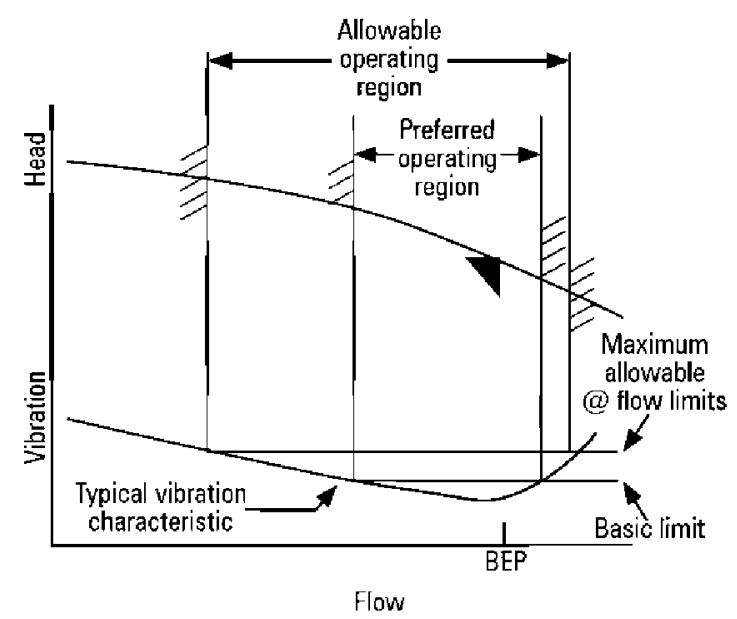


Fig.4. Preferred operating region to bring about the lowest energy and maintenance cost and to reduce the risk of system problems since hydraulic excitation forces and cavitation risk attain a minimum close to the BEP [38].

A pump selected with the duty point in a low water-flow rate range (Pump C) may have problems due to increased internal turbulence, recirculation, increased pressure fluctuations and vibrations, increased axial and radial thrust, and rise in temperature due to the high internal energy loss. On the other hand, pump selected in proximity to the maximum allowable water-flow rate (Pump A) may have problems of cavitation.

To illustrate this method, let us imagine a case in which it is necessary to pump a water flow of $\mathrm{Q}=227 \mathrm{~m}^{3} / \mathrm{h}$ from a deep well to a water pool with a total manometric head of $288 \mathrm{~m}(\mathrm{Hst}=270 \mathrm{~m}$ and drawdown plus friction losses of $18 \mathrm{~m})$

The next step is to use any of the tools that the different pump manufacturers offer to select the most suitable pump for this duty point. We will use the PumpTutorNG tool, offered by Caprari [37] but the procedure would be similar with any other tool.

Once the H-Q duty point is introduced, the tool presents the possible pumps that could work at this point. It can be observed in Fig 5 that the tool itself presents the list of suitable pumps ordered according to their efficiency, which shows that this is the main criteria when selecting a pump. In this case, the pump with the best efficiency at this duty point (79.3\%) is the E12S55/9B+MAC12340C-8V model. Fig 6 shows the H-Q curves of the different possible pumps, in which the one with the best efficiency is highlighted. 


\begin{tabular}{|c|c|c|c|c|c|c|c|c|c|}
\hline 口 & Pump & Model & Code & $\begin{array}{l}\text { Speed } \\
{[1 / \mathrm{min}]}\end{array}$ & $\begin{array}{c}\text { Frequency } \\
{[\mathrm{Hzz}]}\end{array}$ & $\begin{array}{l}\text { DNm } \\
{[\mathrm{mm}]}\end{array}$ & $\begin{array}{c}\text { Efficiency } \\
[\%]]\end{array}$ & $\begin{array}{c}\mathbf{P} 2 \mathbf{m a x} \\
{[\mathrm{kW}]}\end{array}$ & M.E.I. \\
\hline$\square$ & & E12555/98+MAC12340C-8V & 823597 & 2900 & 50 & & 79,3 & 232,8 & \\
\hline$\square$ & & $E 12555 / 9 Q+M 14330-8 V$ & 823299 & 2900 & 50 & & 79,3 & 240 & \\
\hline$\square$ & & E10555/15A+MAC12340C:8V & 823593 & 2900 & 50 & & 78,8 & 224,5 & \\
\hline$\square$ & & E12542/6P+MAC12340C-8V & 823604 & 2900 & 50 & & 78,3 & 231,8 & \\
\hline$\square$ & & E12542/6P+M14330-8V & 822775 & 2900 & 50 & & 77,6 & 295,3 & \\
\hline$\square$ & & $=12550 / 114+M A C 123 \Delta 0 C-8 \mathrm{~V}$ & 823595 & 2900 & 50 & & 76,1 & 227,2 & \\
\hline$\square$ & & $\mathrm{E} 12558 / 8 \mathrm{AB}+\mathrm{M} 14380-8 \mathrm{~V}$ & 823304 & 2900 & 50 & & 74,8 & 278,2 & \\
\hline$\square$ & & E12558/8AB+MAC1240OC-8V & 823637 & 2900 & 50 & & 74,3 & 275,9 & \\
\hline$\square$ & & E14SE50/6W+M14430-8V & 822784 & 2900 & so & & 68,3 & 312,8 & \\
\hline 口 & & E14SE50,6WW+MAC12475C-8V & 823613 & 2900 & 50 & & 68,2 & 308,7 & \\
\hline
\end{tabular}

Fig.5. List of the suitable pumps offered by PumpTutorNG tool for the duty point $\mathrm{H}=$ $288 \mathrm{~m}$ and $\mathrm{Q}=227 \mathrm{~m}^{3} / \mathrm{h}$.

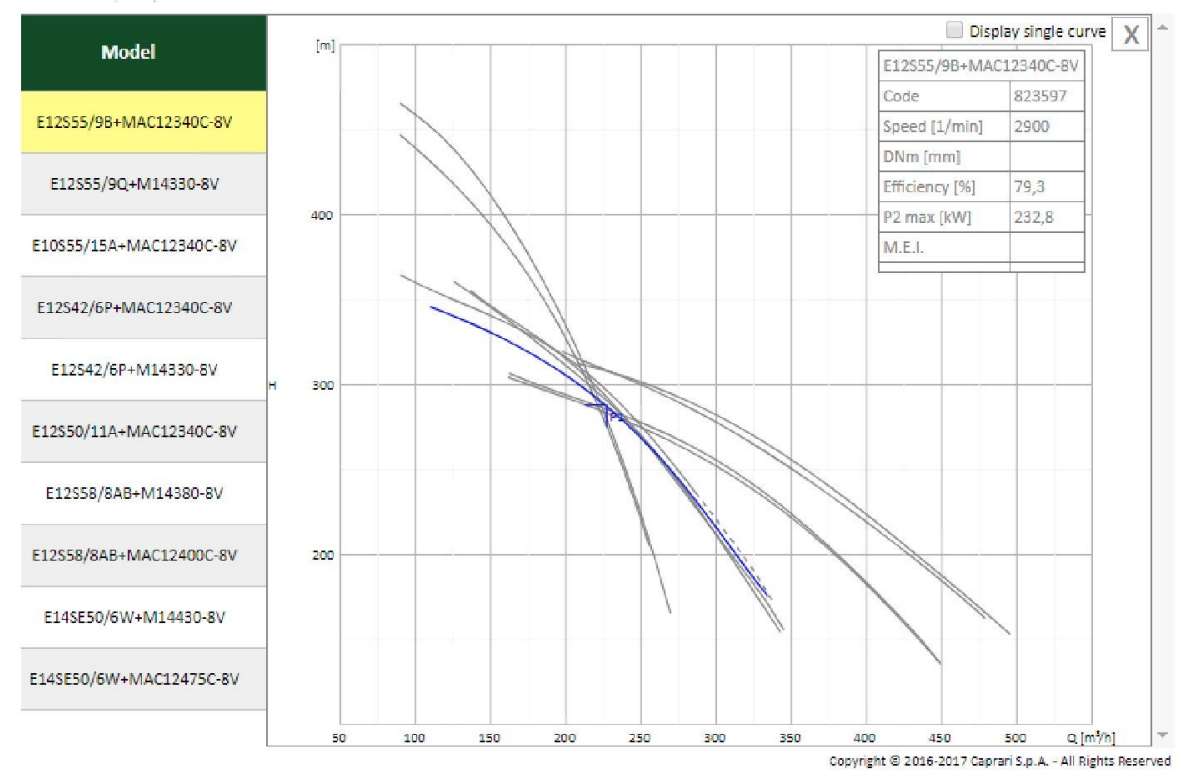

Fig.6. H-Q curves of the pumps offered by PumpTutorNG tool for the duty point $\mathrm{H}=$ $288 \mathrm{~m}$ and $\mathrm{Q}=227 \mathrm{~m}^{3} / \mathrm{h}$.

There is another pump model with the same high efficiency, E12S55/9Q+M14330-8V but it demands slightly more power, so from a technical point of view, the final selected 
pump would be the E12S55/9B+MAC12340C-8V leaving the final decision down to economic aspects.

\section{The new selection method for PV irrigation systems at a variable frequency}

PV irrigation systems are basically made up of a PV generator, a frequency converter and a standard centrifugal pump (Fig. 7).

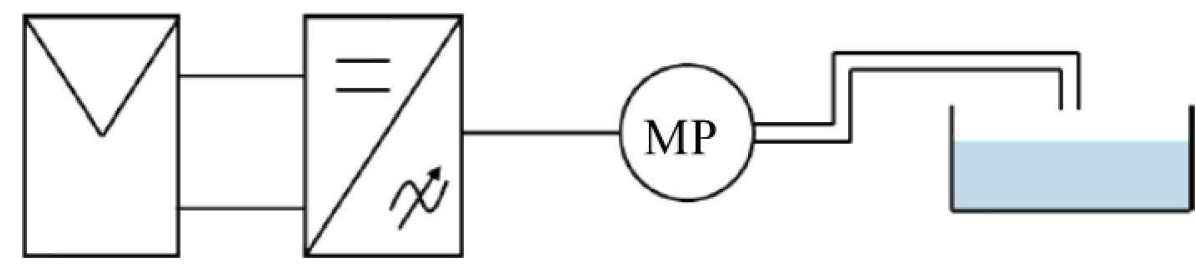

Fig.7. Components of a PV irrigation system: PV generator, frequency converter, motor-pump and water tank.

When working with PV irrigation systems at a variable frequency, by means of a frequency converter, it is possible to vary the rotation speed of the pump by adjusting the operating frequency according to the PV power available. So, it must be assured that, first, the selected pump is able to work at a wide range of frequencies for a certain irrigation system and, second, between a range of high efficiencies. These conditions are satisfied if the pump has an H-Q curve with a high slope to allow a wide range of intersection points between the system curve and the H-Q curves of the pump at different frequencies. So, the new pump selection method would have the following four steps: 
a. To select the pumps with an H-Q curve at $50 \mathrm{~Hz}$ with the greatest slopes from those that can work at a certain duty point.

b. To select the pumps (from the previous ones) in which the duty point is in the "right-hand third" of the H-Q curve. The duty point at the right-hand part of the H-Q curve, together with its great slope, will allow a wide range of operating frequencies

c. To identify the lowest operating frequency at which the pump is able to elevate water into the pool. It will be defined by the H-Q curve with the lowest frequency that intersects with the system curve. The pumps with the lowest frequencies will be preferable, as they will allow a wider range of operating frequencies.

d. To select the pump with the best efficiency between those fulfilling the previous steps.

Let us illustrate this method by applying it to the example set out in the previous section.

a) To select the pumps with an H-Q curve at $50 H z$ with the greatest slopes The two pumps with the greatest slopes from among those that cover the duty point are those marked in blue in Fig 8. They are the models E10S55/15A+MAC12340C-8V and E12S50/11A+MAC12340C-8V. Observe that, in the first one, the ratio between the lowest $(200 \mathrm{~m})$ and the highest pumping head $(460 \mathrm{~m})$ is 2.3 , while in the second one is 2.0 (from $215 \mathrm{~m}$ to $430 \mathrm{~m}$ ). 


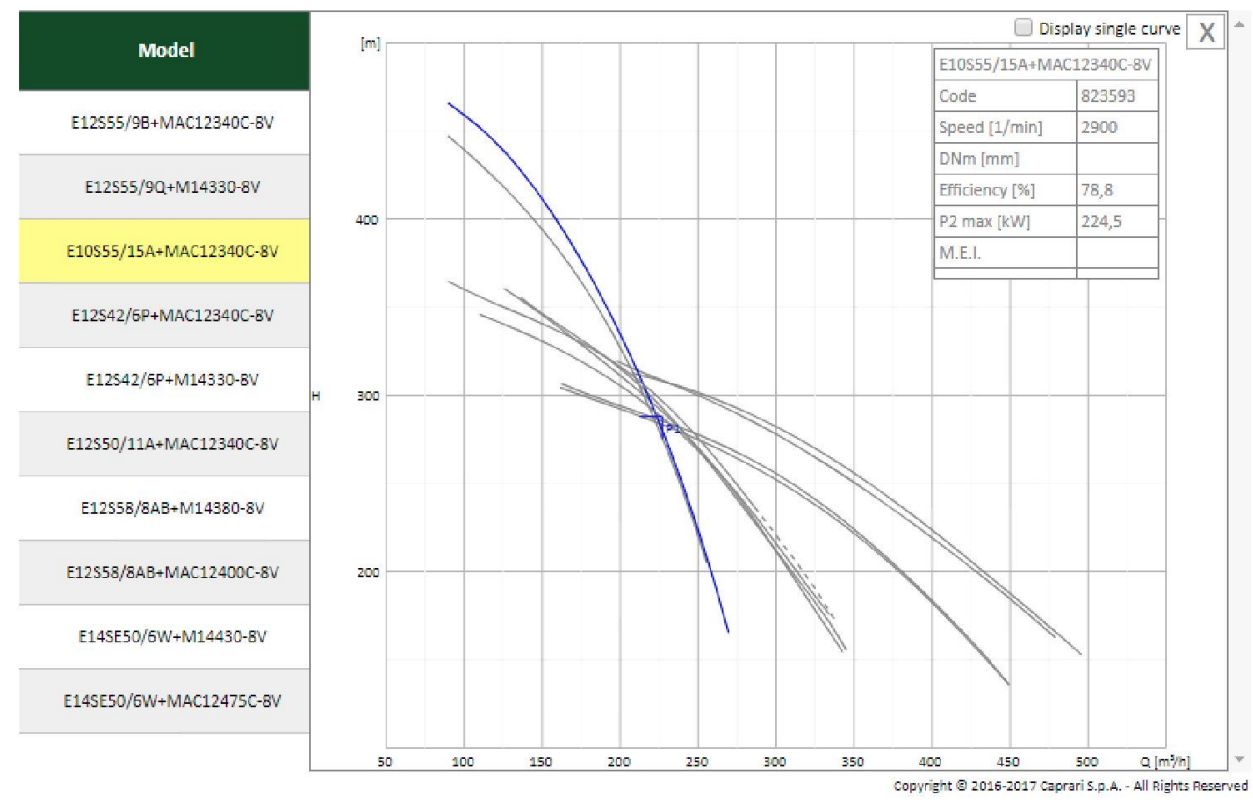

(a)

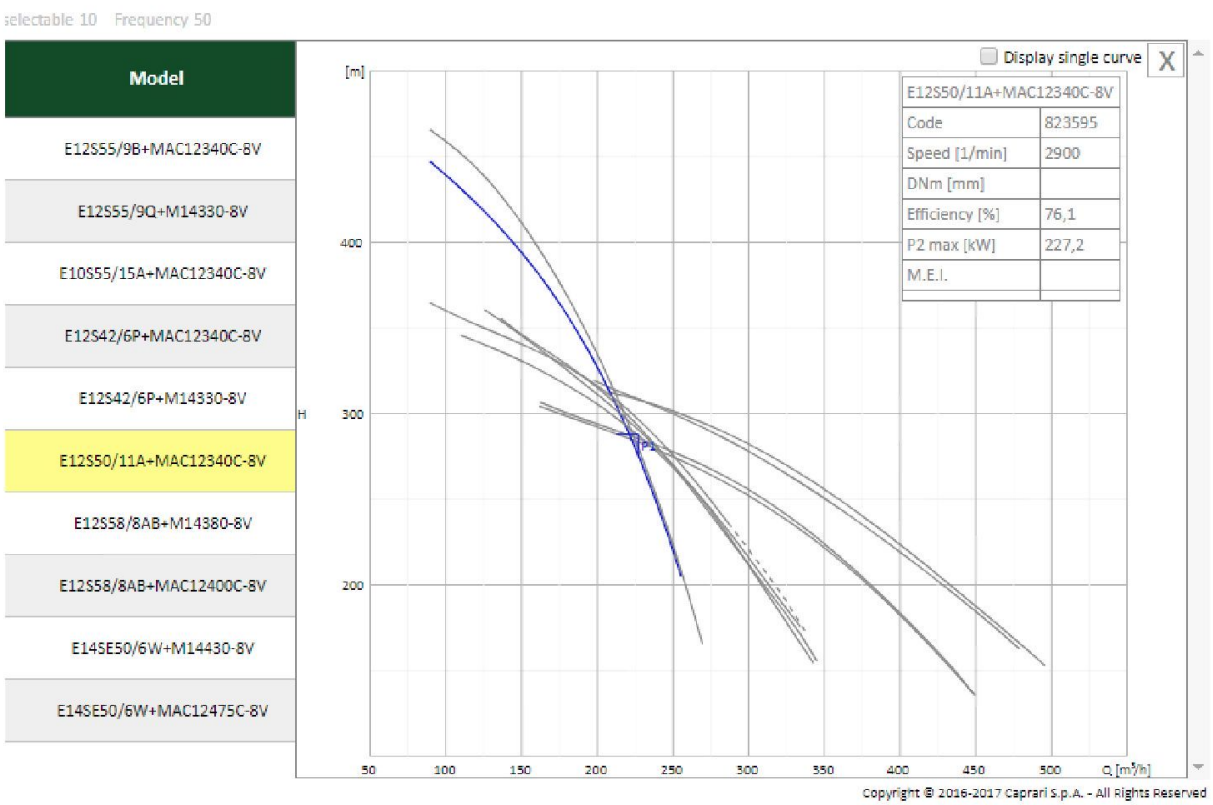

(b)

Fig.8. Pumps with the highest slope. The E10S55/15A+MAC12340C-8V (a) and E12S50/11A+MAC12340C-8V (b) models show the ratio between the lowest and the highest head of 2.3 and 2.0 respectively.

b) To select the pump with the duty point in the right-hand third of the $H-Q$ curve 
Fig 9 shows the H-Q curve of both pumps in detail. They differ slightly in the slope and the efficiency curve but both of them have the duty point (marked as P1 in Fig 9) in the right-hand third of the H-Q curve.

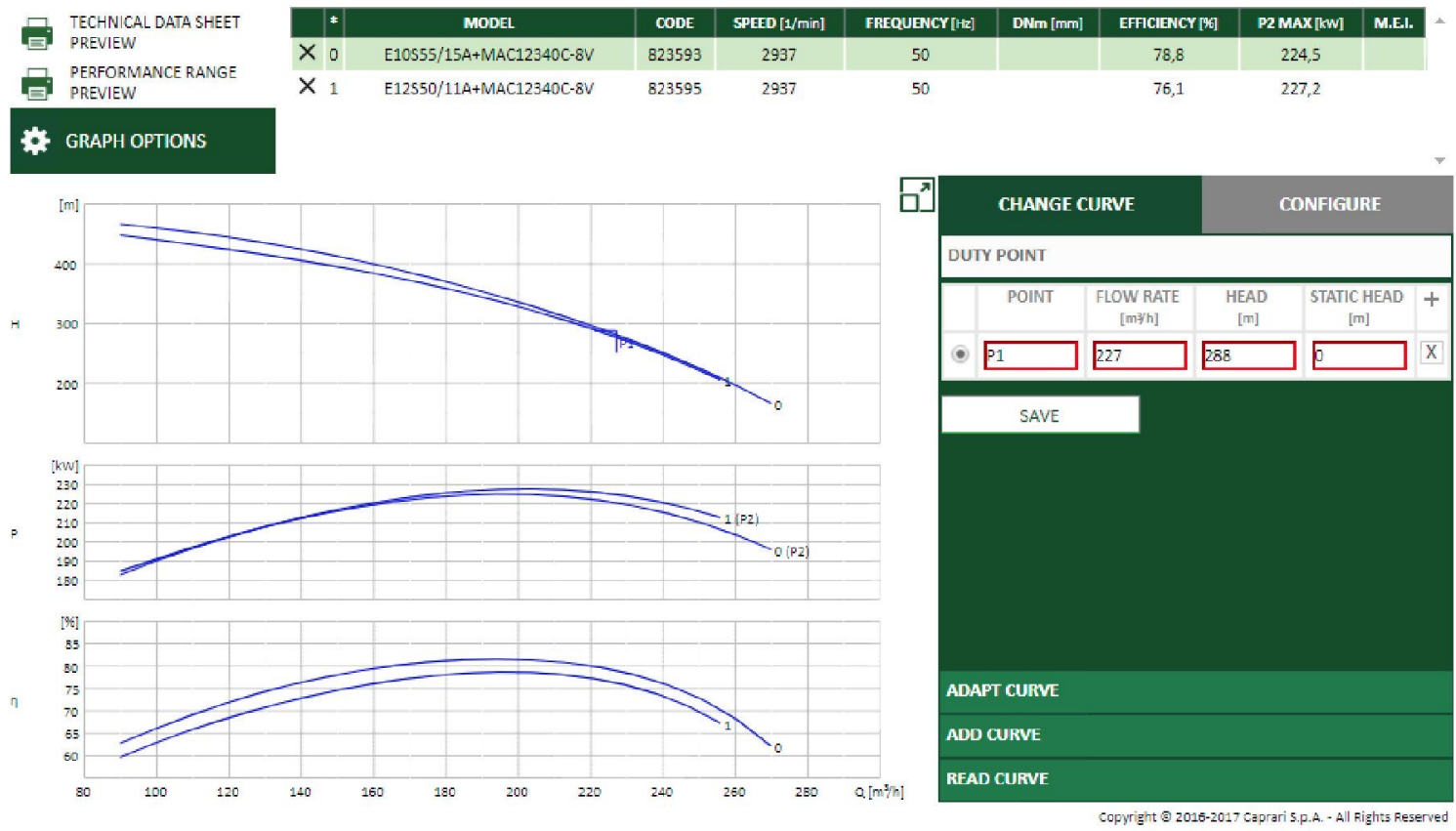

Fig.9. Detail of the H-Q, power-Q and efficiency-Q of both pumps. In both cases, the duty point is in the right-hand third of the H-Q curve.

c) To identify the lowest operating frequency at which the pump is able to elevate water into the pool

The procedure for finding the lowest frequency that allows pumping with a certain pump consists of drawing the system curve together with the pump H-Q curve at different frequencies. The pump H-Q curves crossing the system curves correspond to frequencies that allow pumping. The lowest operating frequency is that whose H-Q curve is tangent to the system curve. 
The minimum frequency for pumping in the case of E10S55/15A+MAC12340C-8V is $38 \mathrm{~Hz}$, as shown in Fig $10 \mathrm{a}$, while in the case of E12S50/11A+MAC12340C-8V it is $39 \mathrm{~Hz}$, as shown in Fig $10 \mathrm{~b}$.

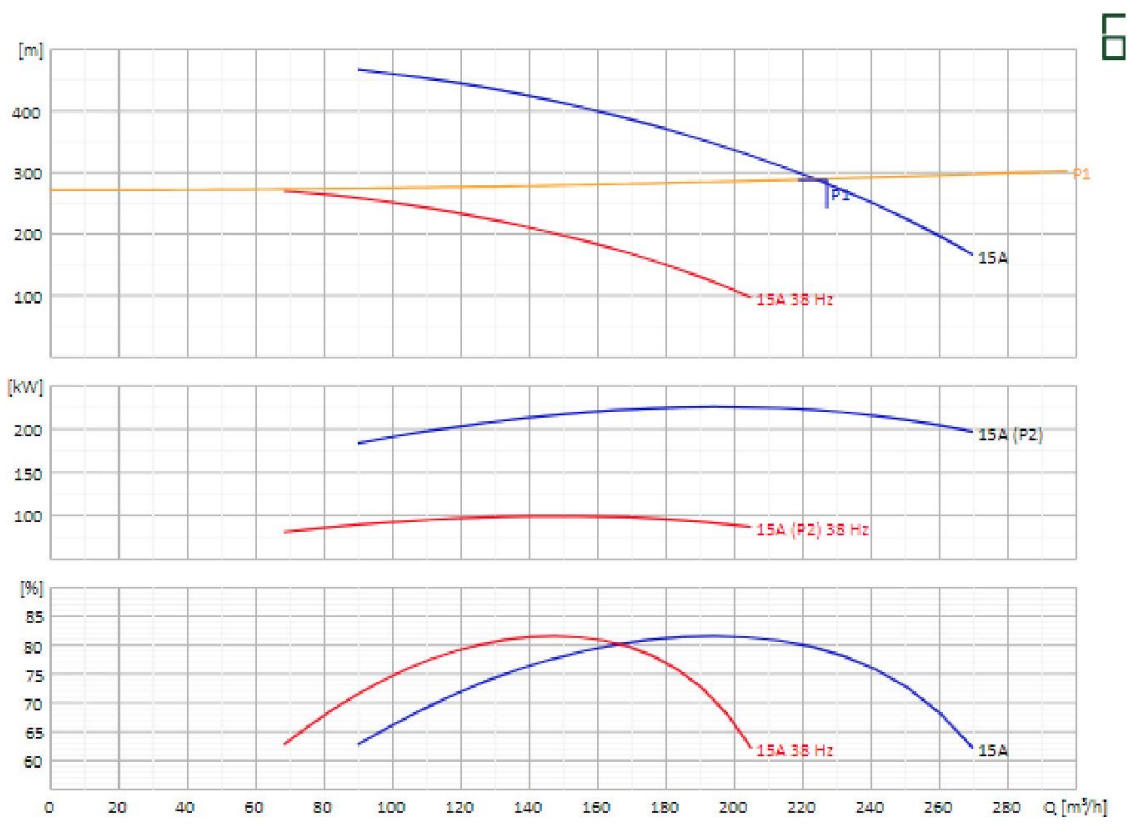

(a)
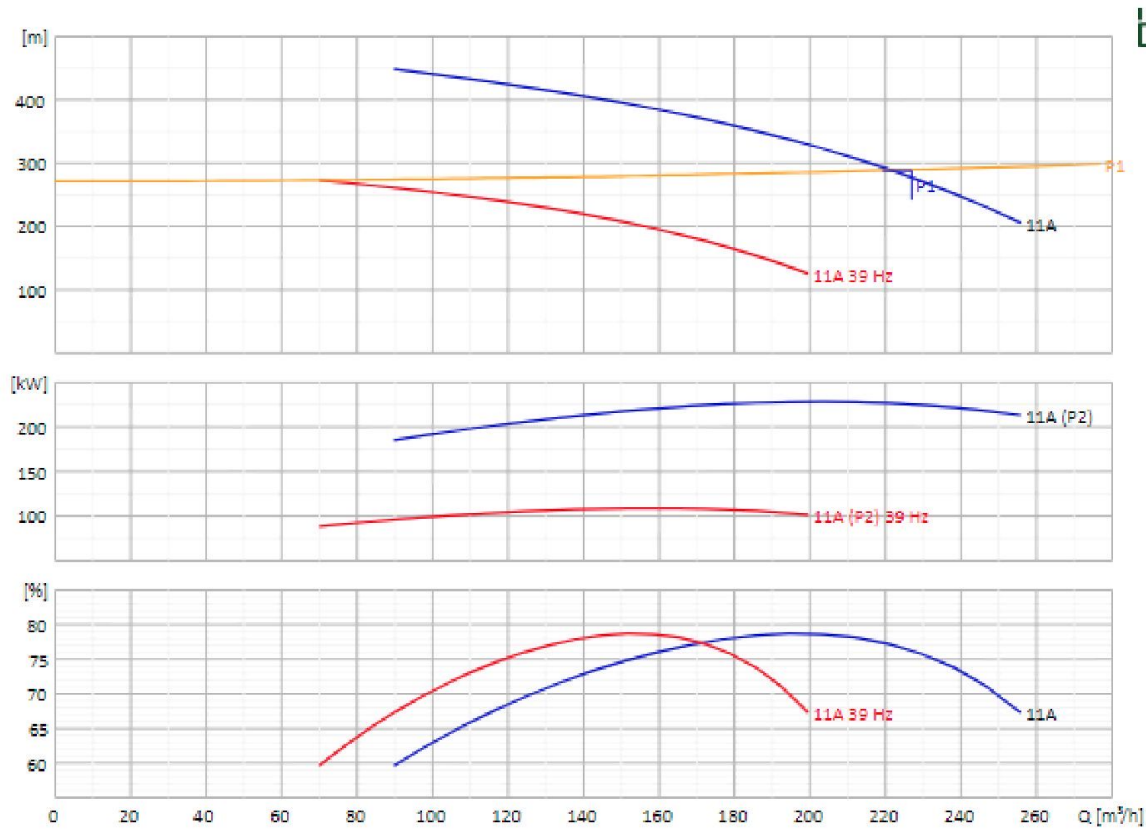

(b) 
Fig.10. Determination of the lowest operating frequency for the E10S55/15A+MAC12340C-8V pump (a) and the E12S50/11A+MAC12340C-8V pump (b). The values are $38 \mathrm{~Hz}$ and $39 \mathrm{~Hz}$ respectively.

\section{d) To select the pump with the best efficiency}

The efficiency of a pump depends on the operating frequency. So, in order to analyse the efficiency, it is necessary to evaluate its values at different frequencies. Obviously, in the design stage, the necessary data to evaluate the energy efficiency are not available. So, for design purposes, we will evaluate the power efficiency at four different operating frequencies (maximum, $\eta_{\max }$, minimum, $\eta_{\min }$, and two intermediate frequencies, $\eta_{\text {int1 }}$ and $\left.\eta_{\text {int2 }}\right)$ and we define an energy "Irrigation efficiency", $E F F_{\text {IRR }}$, in accordance with the following equation:

$E F F_{\mathrm{IRR}}=0.125 \eta_{\min }+0.125 \eta_{\text {int1 }}+0.25 \eta_{\text {int2 }}+0.50 \eta_{\max }$

Fig $11 \mathrm{a}$ and $\mathrm{b}$ shows the efficiency curves at the aforementioned frequencies for both pumps. Only the efficiency values for $50 \mathrm{~Hz}$ are shown but the procedure is similar for the rest of the frequencies. By applying Eq[1], the resulting $E F F_{\text {IRR }}$ for both pumps are shown in Table 1. 


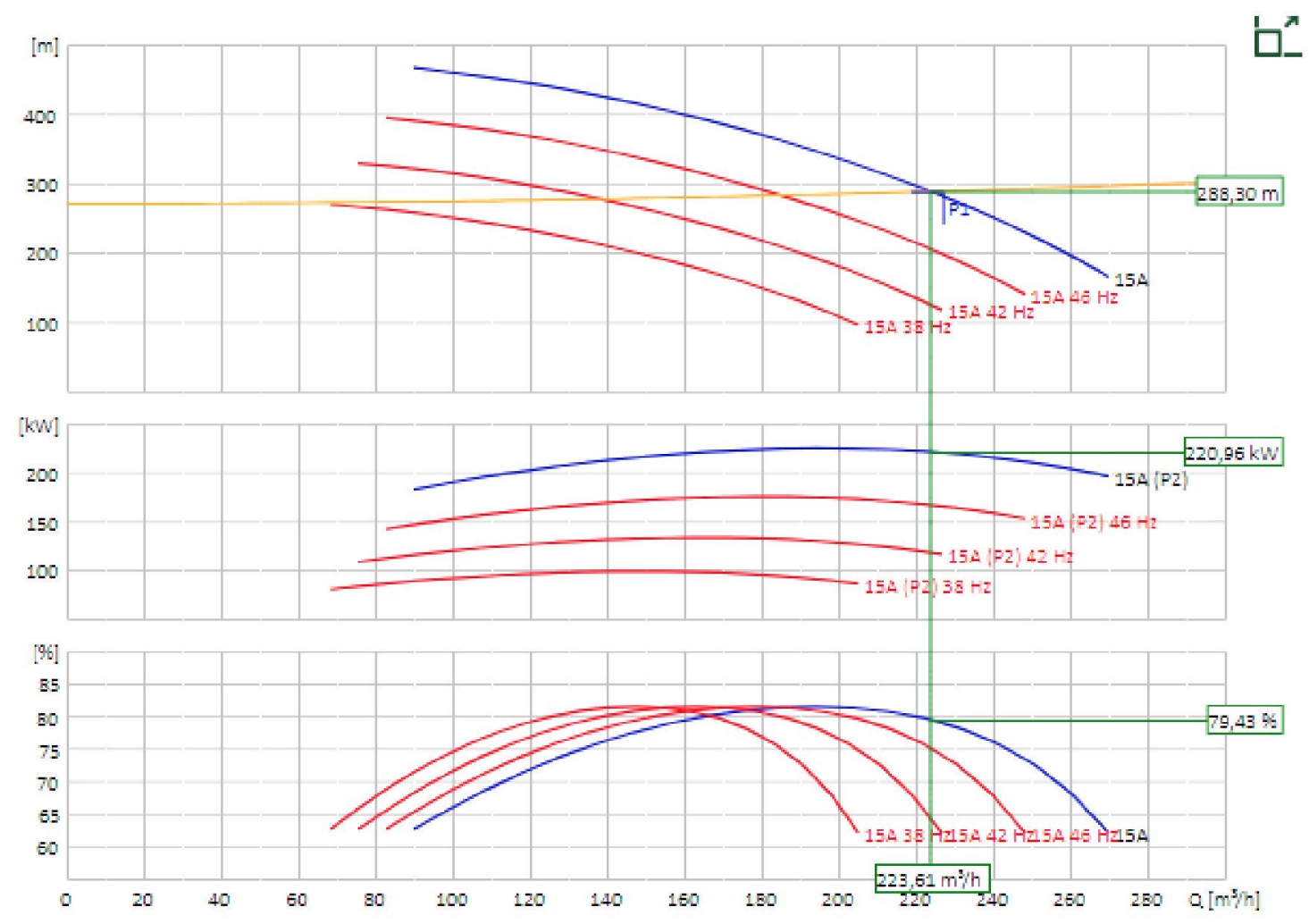

(a)

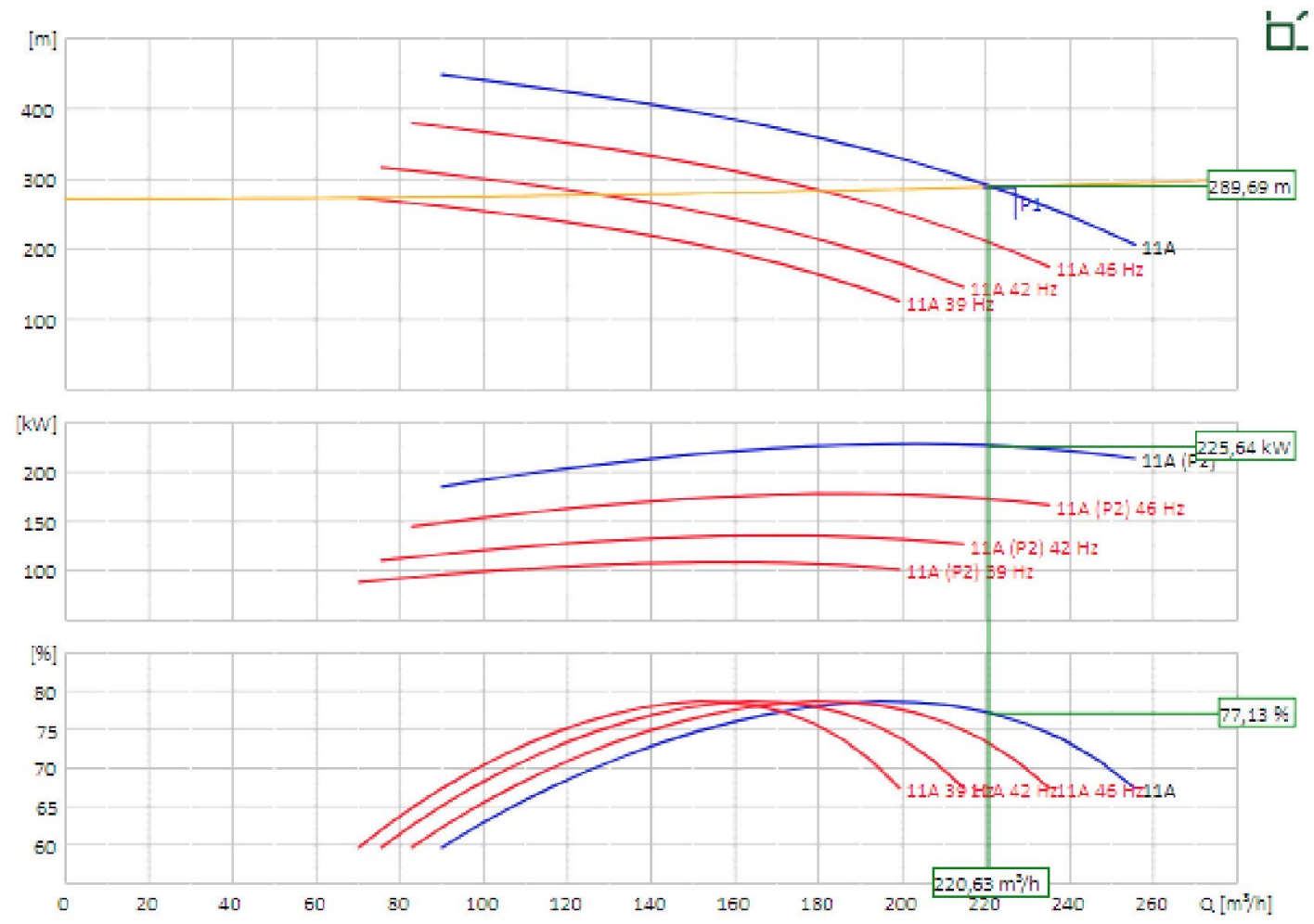

(b) 
Fig.11. H-Q, power-Q and efficiency-Q curves at the frequencies used to calculate $E F F_{\text {IRR }}$ for the E10S55/15A+MAC12340C-8V pump (a) and the E12S50/11A+MAC12340C-8V pump (b). Only the efficiency values for $50 \mathrm{~Hz}$ are shown but the procedure is similar for the rest of the frequencies.

Table 1. Values of the pump efficiency at the four frequencies used to calculate $E F F_{\text {IRR. }}$.

\begin{tabular}{|c|c|c|}
\hline & E10S55/15A+MAC12340C-8V & E12S50/11A+MAC12340C-8V \\
\hline$\eta_{\max }[\%]$ & 79.43 & 77.13 \\
\hline$\eta_{\text {int2 }}[\%]$ & 81.29 & 78.53 \\
\hline$\eta_{\text {int1 }}[\%]$ & 79.93 & 74.87 \\
\hline$\eta_{\min }[\%]$ & 63.18 & 60.36 \\
\hline $\boldsymbol{E F F}_{\text {IRR }}[\%]$ & $\mathbf{7 7 . 9 3}$ & $\mathbf{7 5 . 1 0}$ \\
\hline
\end{tabular}

According to the results, the selected pump would be the E10S55/15A+MAC12340C$8 \mathrm{~V}$ with a $E F F_{\text {IRR }}$ of $77.93 \%$ and a frequency range from $38 \mathrm{~Hz}$ to $50 \mathrm{~Hz}$.

It is interesting to note that the efficiency of the pump selected with the traditional method (E12S55/9B+MAC12340C-8V) is $E F F_{\text {IRR }}=75.01 \%$ and the frequency range is from $44 \mathrm{~Hz}$ to $50 \mathrm{~Hz}$.

Accordingly, with the new proposed method, the range of working frequencies is higher than that of the traditional one, and the $E F F_{\text {IRR }}$ is also better. Although the pump may work in a low water-flow region further away from the BEP, the low water-flow problems highlighted in section 2 are not expected to happen because this condition only occurs for limited periods at a low rotation speed, at a lower power and with a 
lower pump operating pressure than at the duty point. Furthermore, although the duty point in this new method is in the right-hand third of the pump H-Q curve and, therefore, working at a high water flow, it is far from the maximum allowable water flow limit and still within the preferred region of operation. So, cavitation is not likely to occur. Moreover, the selection of the duty point to the right of the BEP allows the pump to work at a high efficiency even at reduced frequencies, working at low efficiency only at extremely low frequencies that occur just for a limited time, in the start-up phase at sunrise and in the shutdown phase at sunset.

\section{Pump selection method and PV irrigation system performance}

The comparison of the performance of the same PV irrigation system with the two pumps selected with both the traditional and the proposed method is carried out using the SISIFO tool [40] - an open simulation tool for PV systems which includes the possibility of simulating PV irrigation systems [11] using irradiation values for Madrid from the PVGIS database [41]

The main characteristics of the components of the system are summarized in Table 2 together with the main information of the hydraulic system curve. For the PV generator, we have used the M Prime 3R PLUS of $250 \mathrm{Wp}$ PV modules mounted on a North-South horizontal axis tracker with backtracking to avoid mutual shadows, a ground cover ratio of $1 / 3$ and a maximum rotation angle of $45^{\circ}$.

Table 2. PV generator size, inverter and pumping characteristics.

\begin{tabular}{|l|l|}
\hline Parameter & Value/ option \\
\hline
\end{tabular}




\begin{tabular}{|c|c|}
\hline PV generator size [kWp] & 360 \\
\hline Nominal power of the FC [kW] & 315 \\
\hline Type of PV irrigation system & Stand-alone \\
\hline Type of pumping & Water pool \\
\hline Static head [m] & 270 \\
\hline Friction losses at rated flow [m] & 18 \\
\hline Working flow [m $\left.\mathbf{m}^{\mathbf{3}} \mathbf{h}\right]$ & 227 \\
\hline
\end{tabular}

Table 3 details the results of the performance of both pumps, in terms of volume of water per $\mathrm{kWp}$ of nominal power of the PV generator and in terms of the annual efficiency of the pump. Fig 12 shows the monthly volume of water pumped with both pumps.

Table 3. Performance and annual efficiency of both pumps, that selected with the new method proposed here and that selected with the traditional method

\begin{tabular}{|c|c|c|}
\hline Parameter & $\begin{array}{c}\text { Proposed method } \\
\text { E10S55/15A+MAC12340C-8V }\end{array}$ & $\begin{array}{c}\text { Traditional method } \\
\text { E12S55/9B+MAC12340C-8V }\end{array}$ \\
\hline $\begin{array}{l}\text { Performance } \\
\left.\qquad \mathbf{m}^{\mathbf{3}} / \mathbf{k W p}\right]\end{array}$ & 1779 & 1476 \\
\hline $\begin{array}{l}\text { Annual pump } \\
\text { efficiency [\%] }\end{array}$ & 78.54 & 75.27 \\
\hline
\end{tabular}




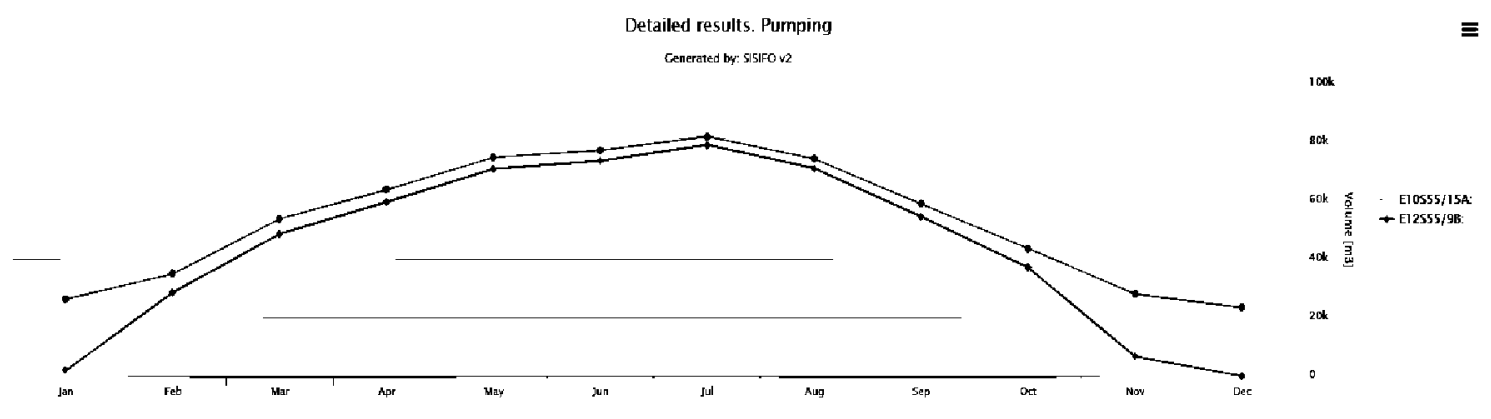

Fig. 12. Monthly yield with both the proposed pump and the traditional one.

The results show that the proposed pump selection method translates into an increase in the performance of $20.5 \%$. This increase is basically due to the wider range of operating frequencies that allows the daily hours of pumping to be expanded and the increase in the pump efficiency of $4.3 \%$. To illustrate this, Table 4 shows the comparison of the time and water flow of both pumps at the start, at the duty point and at the end during the characteristic days of the months of May, June and July. It can be observed that the E10S55/15A+MAC12340C-8V (Pump A in Table 4) has a longer period of pumping and higher daily volume of water pumped due to its wider range of operating frequencies.

Table 4. Performance comparison of the pumps selected with the new (Pump A: E10S55/15A+MAC12340C-8V) and the traditional method (Pump B: E12S55/9B+MAC12340C-8V) in the characteristic days of of May, June and July.

\begin{tabular}{|c|c|c|c|c|c|c|c|c|}
\hline \multirow{2}{*}{$\begin{array}{c}\text { Charac- } \\
\text { teristic } \\
\text { day }\end{array}$} & \multirow[b]{2}{*}{ Pump } & \multicolumn{2}{|c|}{ Start } & \multicolumn{2}{|c|}{ Duty point } & \multicolumn{2}{|c|}{ End } & \multirow{2}{*}{$\Sigma \mathbf{Q}$} \\
\hline & & $\begin{array}{c}\text { h } \\
\text { [hh:mm] }\end{array}$ & $\begin{array}{c}\mathbf{Q} \\
{\left[\mathrm{m}^{3} / \mathrm{h}\right]}\end{array}$ & $\begin{array}{c}h \\
\text { [hh:mm] }\end{array}$ & $\begin{array}{c}\mathbf{Q} \\
{\left[\mathbf{m}^{3} / \mathbf{h}\right]}\end{array}$ & $\begin{array}{c}h \\
\text { [hh:mm] }\end{array}$ & $\begin{array}{c}\mathbf{Q} \\
{\left[\mathbf{m}^{3} / \mathbf{h}\right]}\end{array}$ & \\
\hline May & $\mathbf{A}$ & $5: 57$ & 91 & $9: 01-11: 11$ & $219-220$ & $17: 59$ & 91 & 2412 \\
\hline
\end{tabular}




\begin{tabular}{|c|c|c|c|c|c|c|c|c|}
\hline & B & $6: 14$ & 111 & $9: 15-10: 42$ & $219-220$ & $17: 41$ & 111 & $\mathbf{2 2 8 7}$ \\
\hline \multirow{3}{*}{ June } & $\mathbf{A}$ & $5: 39$ & 91 & $8: 28-14: 40$ & $219-224$ & $18: 16$ & 91 & $\mathbf{2 5 7 1}$ \\
\cline { 2 - 9 } & $\mathbf{B}$ & $5: 57$ & 111 & $8: 35-14: 22$ & $219-224$ & $17: 58$ & 111 & $\mathbf{2 4 5 2}$ \\
\hline \multirow{3}{*}{ July } & $\mathbf{A}$ & $5: 41$ & 91 & $7: 55-15: 31$ & $219-231$ & $18: 14$ & 91 & $\mathbf{2 6 4 1}$ \\
\cline { 2 - 9 } & $\mathbf{B}$ & $5: 57$ & 111 & $8: 00-15: 24$ & $219-231$ & $17: 58$ & 111 & $\mathbf{2 5 5 2}$ \\
\hline
\end{tabular}

Pump B requires a higher power threshold to start pumping and, therefore, in the one hand, pump A has a longer daily period of pumping as seen in Table 4, and in the other hand pump A pumps more water in the winter months with less mean irradiation, as seen in Figure 13. This is the main reason why pump B has less annual energy efficiency $(75.27 \%)$ than pump A (78.54\%) even when their power efficiency at the maximum operating frequency are more similar (pump B: $77.13 \%$ and pump A: $79.43 \%$ ). These similar efficiency values of at the maximum operating frequency are also the reason for having similar water flows at the duty point

A similar simulation has been performed for Marrakech (Morocco) and Nice (France), two different locations in terms of latitude, total annual solar radiation and ambient temperature, both in the Mediterranean zone. The comparative results between pump A and pump B show an increase in the pumped water of $7.2 \%$ for Marrakech and $21.0 \%$ for Nice as well as an increase in the pump efficiency of $4.3 \%$ for Marrakech and $5.3 \%$ for Nice. These differences are presented in Table 5 and the variation in the performance is mainly due to the latitude: the higher the latitude, the higher the increase in the performance. This is due to the north-south tracker used in large-power irrigation systems that performs better in winter for latitudes closer to the equator. This way, the power threshold to elevate water with Pump B is reached more frequent in winter 
months in Marrakech but, even in this case, the increased volume of pumped water is $7.2 \%$.

Table 5. Increase in the pumped water and efficiency obtained with the pump selected with the new method proposed here for to other locations: Marrakech and Nice.

\begin{tabular}{|c|c|c|}
\hline Parameter & Marrakech & Nice \\
(Morocco) & (France) \\
\hline Increase in the pumped water [\%] & 7.2 & 21.0 \\
\hline Increase in the pump efficiency [\%] & 4.3 & 5.3 \\
\hline
\end{tabular}

The previous results illustrate the advantages of the new pump selection method for PV irrigation applications but it is worth highlighting that a totally correct pump selection from all points of view also requires other factors to be considered that generally contribute to the selection: type of pump, construction materials, type of water to be pumped, characteristics of the well and of the irrigation system. The most important one is the resistance to wear in case of water with silt/sand. Only a skilled pump technician can identify the most suitable pump in these cases. Another important factor for submersible pumps is the variability with time of the water table in the well: if the water table decreases every year, for example, due to overexploitation of the well, it will be necessary to consider the current hydraulic conditions to select the pumps as well as future ones. In conclusion, this new pump selection method means an alternative basis for the correct design of PV irrigation systems but it will not substitute the validation of an expert pumping technician. 


\section{Implementation in SISIFO}

This new pump selection method has already been implemented in the aforementioned SISIFO tool. Once the duty point is defined, it allows the user to opt for the tool to show just the pumps with a high slope, all of the pumps that work at the duty point or just specific pump models introduced by the user. In any case, SISIFO shows the H-Q curves of the shown pumps for the user to check their slope and the relative position of the duty point. Thus, the user will be able to apply the pump selection method proposed here (see Fig 13).

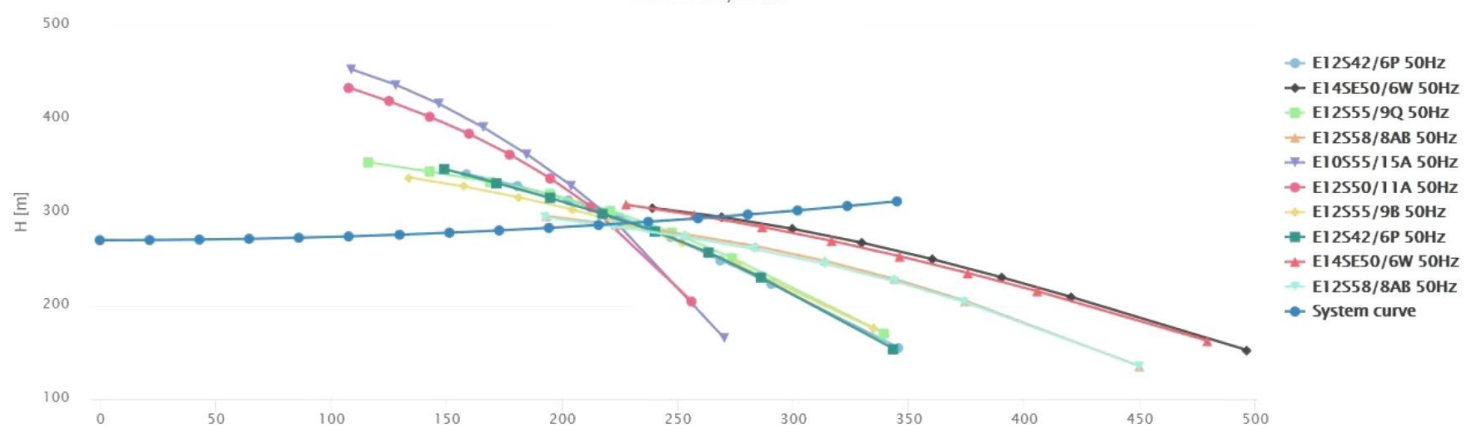

(a)

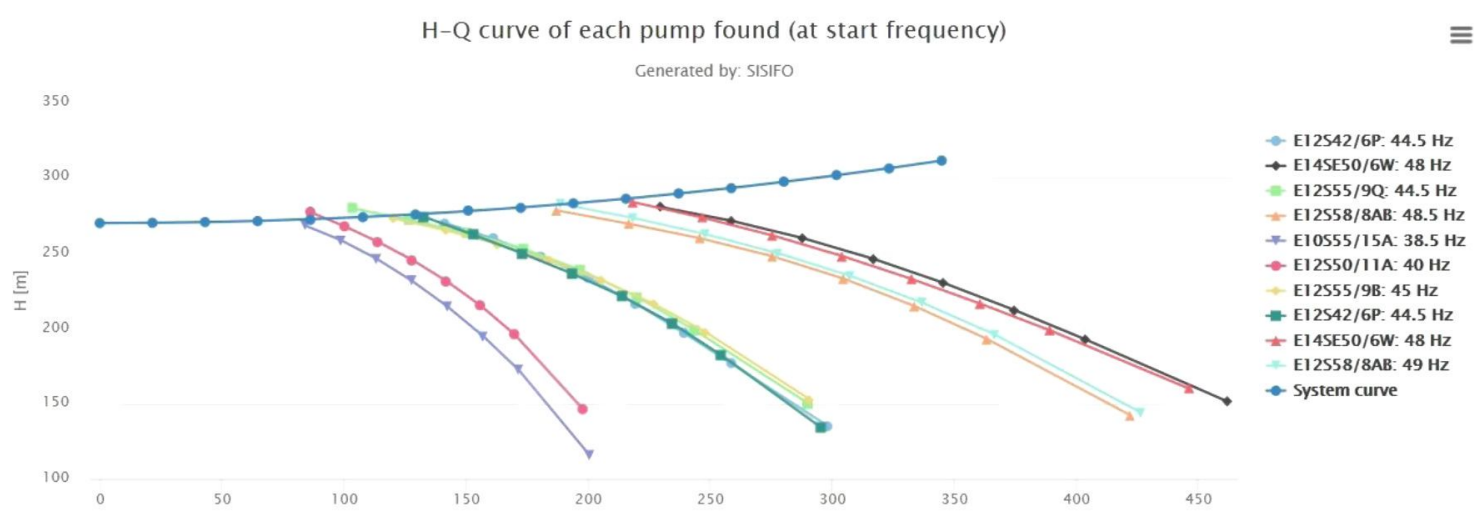

(b)

Fig.13. Comparison of the H-Q curves of several possible pumps for a certain duty point as shown by SISIFO - curves at $50 \mathrm{~Hz}$ are shown in (a), while the ones at start frequency are in (b). The system curve is also included. 
Moreover, SISIFO allows the simulation of the whole PV irrigation system in a certain location with just the selected pump or with a set of possible pumps for comparing their performance. SISIFO delivers the total volume of water as output during the whole year or during an irrigation period defined by the user. It also allows the monthly, daily or hourly water pumped in the characteristics days of the months of interest to be compared (Fig 14). Thus, from the base of the proposed pump selection method, fine tuning of the selection is possible.

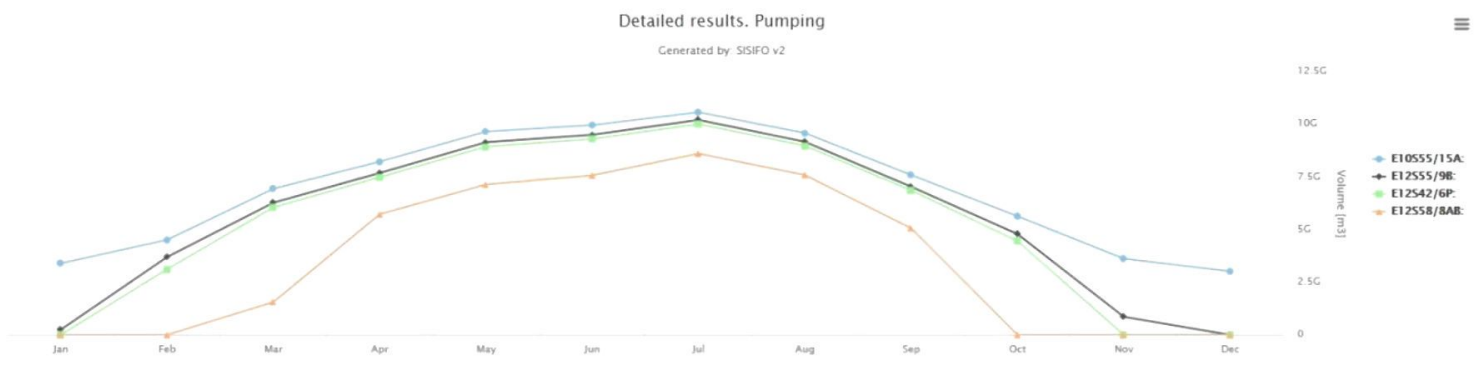

a

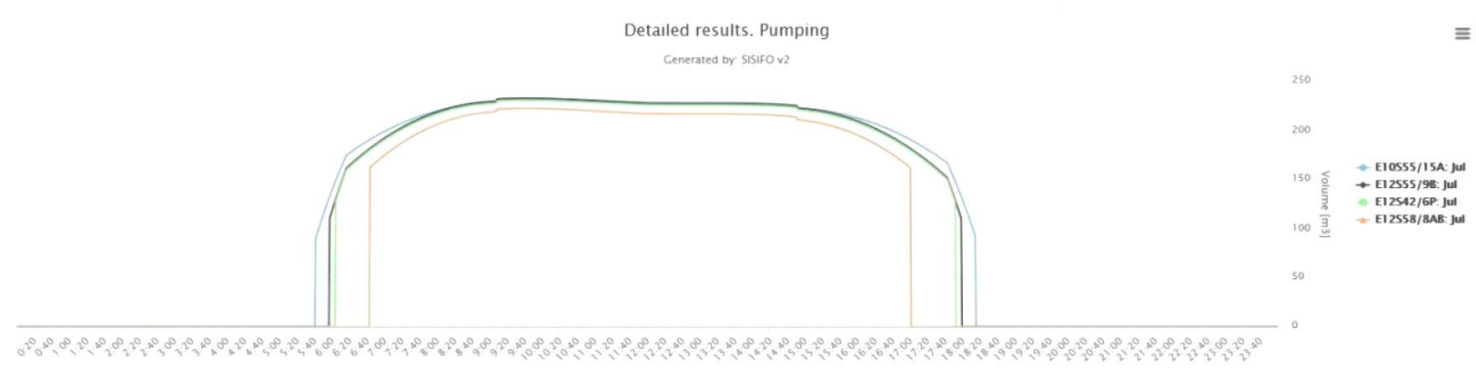

b

Fig.14. Comparison of the volume of water pumped by four possible pumps during (a) the twelve months of a year and (b) during the pumping hours of the characteristic day of July. 
The implementation of this method in SISIFO integrates the usefulness of the traditional tools for selecting pumps, usually offered by pump manufacturers, and the possibility of simulating the performance of PV irrigation systems by taking into account the variable water-flow depending on the PV-power available.

\section{Conclusion}

As traditional pump selection methods were based on maximizing the pump efficiency at the duty point at a certain single operating frequency, they were not useful for PV irrigation systems that work at a variable frequency.

This paper has presented a new pump selection method that, first considers the pumps with H-Q curves with a high slope and the duty point in the right-hand third of the curve to assure a wide range of operating frequencies. And second, it evaluates the efficiency in the whole range of frequencies. The usefulness of this new method has been shown by comparing the performance of a PV irrigation system in Madrid, Marrakech and Nice with both pumps, that selected according to the traditional method and that selected with the new proposed one. The results of the simulation with the SISIFO tool show an increase in the total yearly volume of water pumped in the range of $7.3-21.0 \%$ and $4.3-5.3 \%$ in pump efficiency using the proposed pump selection method.

This new method has already been implemented in SISIFO and, therefore, this tool automatically selects the possible pumps for a certain duty point according to this procedure. Moreover, SISIFO allows the fine tuning of the selection through the comparison of the performance of the PV irrigation system with the different pumps on a yearly, monthly, daily or hourly basis. 
In any case, it is worth highlighting that a totally correct pump selection from all points of view requires also other factors to be considered that generally contribute to the selection: type of pump, construction materials, type of water to be pumped, characteristics of the well and of the irrigation system. Only a skilled pump technician can identify the most suitable pump model after considering these factors.

\section{Acknowledgments}

This work has been possible thanks to the funding from the European Union's Horizon 2020 research and innovation programme in the project MArket uptake of an innovative irrigation Solution based on LOW WATer-ENergy consumption (MASLOWATEN), under grant agreement $n^{\circ} 640771$, as well as the financial support by MIT Portugal Program on Sustainable Energy Systems and the Portuguese Science and Technology Foundation (FCT), grant PD/BD/105851/2014, and IDL project (UID/GEO/50019/2013)

\section{References}

[1] R. Knecht and F. P. Baumgartner, "PV-Battery and Diesel Hybrid System for Irrigation of a Farm in Patagonia," in 33rd European Photovotaic Solar Energy Conference and Exhibition, Amsterdam, 2017.

[2] Energías Renovables, "Powen construye una de las mayores plantas de bombeo solar para regadío de España," 1705 2018. [Online]. Available: https://www.energias-renovables.com/fotovoltaica/powen-construye-una-de-las- 
mayores-plantas-20180517. [Accessed 2018].

[3] I. B. Carrêlo, R. H. Almeida, L. M. Carrasco, F. Martínez-Moreno and L. Narvarte, "A 360 kWp PV irrigation system to a water pool in Spain," in 33rd European Photovotaic Solar Energy Conference and Exhibition, Amsterdam, 2017.

[4] Energías Renovables, "Powen instala en el campo de Albacete un bombeo solar para autoconsumo de casi doscientos kilovatios," 2310 2017. [Online]. Available: https://www.energias-renovables.com/fotovoltaica/powen-instala-en-el-campode-albacete-20171023. [Accessed 2018].

[5] I. B. Carrêlo, R. H. Almeida, F. Martínez-Moreno, L. M. Carrasco and L. Narvarte, "A 160 kWp constant pressure PV Irrigation system in Spain," in 33rd European Photovotaic Solar Energy Conference and Exhibition, Amsterdam, 2017.

[6] R. H. Almeida, I. B. Carrêlo, F. Martínez-Moreno, L. M. Carrasco and L. Narvarte, "A 140 kW hybrid PV-diesel pumping system for constant-pressure irrigation," in 33rd European Photovotaic Solar Energy Conference and Exhibition, Amsterdam, 2017.

[7] Innovagri, "El riego solar, una alternativa para rentabilizar el consumo energético," 2505 2016. [Online]. Available: https://www.innovagri.es/comunidad/el-riego-solar-una-alternativa-pararentabilizar-la-energia.html. [Accessed 2018].

[8] R. H. Almeida, I. B. Carrêlo, L. M. Carrasco, F. Martínez-Moreno and L. Narvarte, "Large-scale hybrid PV-Grid irrigation system," in 33rd European Photovotaic Solar 
Energy Conference and Exhibition, Amsterdam, 2017.

[9] EIP Water, "European Innovation Partnership Water - Strategic Implementation Plan," Brussels, 2012.

[10] J. Fernandez Ramos, L. Narvarte Fernandez, R. Hogan Teves de Almeida, I. Barata Carrêlo, L. M. Carrasco Moreno and E. Lorenzo Pigueiras, "Method and control device for photovoltaic pumping systems". Spain Patent ES 2607253 B2, 13 2018.

[11] J. Munoz, J. Carrillo, F. Martínez-Moreno, L. Carrasco and L. Narvarte, “Modeling and simulation of large PV pumping systems," in Proceedings of the 31th European Photovoltaic Solar Energy Conference and Exhibition, Hamburg, 2015.

[12] R. H. Almeida, L. Narvarte and E. Lorenzo, "PV arrays with delta structures for constant irradiance daily profiles," Solar Energy, vol. 171, pp. 23-30, 2018.

[13] T. Khatib, “Design of Photovoltaic Water Pumping Systems at Minimum Cost for Palestine: A Review," Journal of Applied Sciences, vol. 10, pp. 273-2784, 2010.

[14] IRENA, "Renewable Power Generation Costs in 2017," International Renewable Energy Agency, Abu Dhabi, 2018.

[15] R. Langarita, J. Sánchez Chóliz, C. Sarasa, R. Duarte and S. Jiménez, "Electricity costs in irrigated agriculture: A case study for an irrigation sheme in Spain," Renewable and Sustainable Energy Reviews, 2016. 
[16] M. Abu-Aligah, "Design of Photovoltaic Water Pumping Systems and Compare it with Diesel Powered Pump," Jordan Journal of Mechanical and Industrial Engineering, vol. 5, pp. 272-280, 2011.

[17] C. Lorenzo, R. H. Almeida, M. Martínez-Núñez, L. Narvarte and L. M. Carrasco, "Economic assessment of large power photovoltaic irrigation systems in the ECOWAS region," Energy, vol. 155, pp. 992-1003, 2018.

[18] G. Li, Y. Jin, M. W. Akram and X. Chen, "Research and current status of the solar photovoltaic water pumping system - A review," Renewable and Sustainable Energy Reviews, vol. 79, pp. 440-458, 2017.

[19] P. E. Campana, H. Li and J. Yan, "Techno-economic feasibility of the irrigation system for the grassland and farmland conservation in China: Photovoltaic vs. wind power water pumping," Energy Conversion and Management, vol. 103, pp. 311-320, 2015.

[20] X. Gao, J. Liu, J. Zhang, J. Yan, S. Bao, H. Xu and T. Qin, "Feasibility evaluation of solar photovoltaic pumping irrigation system based on analysis of dynamic variation of groundwater table," Applied Energy, vol. 105, pp. 182-193, 2013.

[21] MASLOWATEN, "MASLOWATEN project," 2018. [Online]. Available: www.maslowaten.eu.

[22] D. H. Muhsen, T. Khatib and T. E. Abdulabbas, "Sizing of a standalone photovoltaic water pumping system using hybrid multi-criteria decision making methods," Solar 
Energy, vol. 159, pp. 1003-1015, 2018.

[23] C. Olcan, "Multi-objective analytical model for optimal sizing of stand-alone photovoltaic water pumping systems," Energy Conversion and Management, vol. 100, pp. 358-369, 2015.

[24] P. E. Campana, H. Li and J. Yan, "Dynamic modelling of a PV pumping system with special consideration on water demand," Applied Energy, vol. 112, pp. 635-645, 2013.

[25] A. A. Ghoneim, "Design optimization of photovoltaic powered water pumping systems," Energy Conversion and Management, vol. 47, pp. 1449-1463, 2006.

[26] A. Boutelhig, S. Hanini and A. H. Arab, "Performances' investigation of different photovoltaic water pumping system configurations for proper matching the optimal location, in desert area," Energy Conversion and Management, vol. 151, pp. 439-456, 2017.

[27] Renu, B. Bora, B. Prasad, O. Sastry, K. Kumar and M. Bangar, "Optimum sizing and performance modeling of Solar Photovoltaic (SPV) water pumps for different climatic conditions," Solar Energy, vol. 155, pp. 1326-1338, 2017.

[28] D. H. Muhsen, A. B. Ghazali and T. Khatib, "Multiobjective differential evolution algorithm-based sizing of a standalone photovoltaic water pumping system," Energy Conversion and Management, vol. 118, pp. 32-43, 2016.

[29] I. Yahyaoui, A. Atieh, A. Serna and F. Tadeo, "Sensitivity analysis for photovoltaic 
water pumping systems: Energetic and economic studies," Energy Conversion and Management, vol. 135, pp. 402-415, 2017.

[30] B. Bouzidi, "New sizing method of PV water pumping systems," Sustainable Energy Technologies and Assessments, vol. 4, pp. 1-10, 2013.

[31] Y. Bakelli, A. H. Arab and B. Azouic, "Optimal sizing of photovoltaic pumping system with water tank storage using LPSP concept," Solar Energy, vol. 85, pp. 288-294, 2011.

[32] H. Suehrcke, J. Appelbaum and B. Reshef, "Modelling a permanent magnet DC motor/centrifugal pump assembly in a photovoltaic energy system," Solar Energy, vol. 59, pp. 37-42, 1997.

[33] A. Hamidat and B. Benyoucef, "Mathematic models of photovoltaic motor-pump systems," Renewable Energy, vol. 33, 2008.

[34] A. D. Gherbi, A. H. Arab and H. Salhi, "Improvement and validation of PV motorpump model for PV pumping system performance analysis," Solar Energy, vol. 144, pp. 310-320, 2017.

[35] M. A. Abella, E. Lorenzo and F. Chenlo, "PV Water Pumping Systems Based on Standard Frequency Converters," Prog. Photovolt: Res. Appl., vol. 11, pp. 179-191, 2003.

[36] Z. Gao, Y. Zhang, L. Gao and R. Li, "Progress on Solar Photovoltaic Pumping Irrigation Technology," Irrigation and Drainage, vol. 67, pp. 89-96, 2018. 
[37] Caprari, “iPump - Caprari," Caprari, [Online]. Available:

https://ipump.caprarinet.net. [Accessed 2018].

[38] J. F. Gülich, Centrifugal Pumps, Springer, 2010.

[39] E. Larralde and R. Ocampo, "Centrifugal pump selection process," World Pumps, pp. 21-28, 2010.

[40] Instituto de Energía Solar - Universidad Politécnica de Madrid, "SISIFO - Simulación de Sistemas Fotovoltaicos," [Online]. Available: https://sisifo.info/.

[41] European Commission, Joint Research Centre, "Photovoltaic Geographical Information System (PVGIS)," [Online]. Available: http://re.jrc.ec.europa.eu/pvgis/. 